\title{
EL MEDIO FÍSICO Y LA PRESA DE ROMÁN (JUMILLA): UN EMPLAZAMIENTO FAVORABLE
}

Alfredo Morales Gil

Margarita Box Amorós

Juan Antonio Marco Molina

\begin{abstract}
RESUMEN
La presa de Román, enclavada en la rambla de la Raja (Jumilla, Murcia), es un azud de derivación de aguas de avenida para el riego, cuya construcción remonta sus orígenes a época romana. El aprovechamiento de aguas eventuales y de las procedentes de la escorrentía hipodérmica, se efectúa mediante una sólida obra de fábrica que, hoy en desuso, es buena prueba del equilibrio entre hombre y medio físico existente hasta hace tres décadas.

\section{RÉSUMÉ}

Le barrage de «Román», situé dans le ravin «de la Raja» (Jumilla, Murcia), c'est una digue dont l'origine remonte dans l'époque romaine, construide pour la dérivation des eaux d'inondation. L'utilisation des eaux éventuelles et des eaux de ruissellement hypogé est garantie par une construction solide -non plus utilisée à présent- qui montre l'équilibre éxistant entre l'homme et le milieu naturel jusqu'à trois décades avant.
\end{abstract}

\section{El medio físico}

La cuenca vertiente de la rambla de la Raja, en cuyo cauce se encuentra la presa de Román, se sitúa al NE. de la Región de Murcia, y forma parte de la red hidrográfica de la rambla del Moro. Dispuesta de NE., a SW., esta subcuenca queda perfectamente delimitada por las alineaciones de la Rajica de Enmedio y la sierra del Carche al norte, y la umbría de la sierra de la Pila al sur.

El valle-corredor en el que hiende su cauce la rambla de la Raja es una depresión tectónica constituida por los materiales predominantemente margosos datados como tortonienses; mientras, las sierras, además de ser las unidades estructuralmente levantadas, 
presentan litofacies más duras y coherentes, tanto de edad terciaria como secundaria, destacando las calizas eocenas y las dolomías cenomanienses o hettangienses. No obstante, rasgo fundamental de la superficie vertiente es el predominio de materiales margosos, impermeables, de considerable trascendencia en el comportamiento de este aparato fluvial.

Por otra parte, el modelado de la depresión viene definido por la convergencia de glacis procedentes de las alineaciones montañosas. El cauce principal de la rambla de la Raja se instala en la parte central del valle, línea de convergencia, pero en su avance hacia el SW. se desplaza al norte, de manera que discurre prácticamente al pie de la Rajica de Enmedio, ya en las inmediaciones de la presa de Román. Al sur del mismo, se extiende el glacis procedente de la sierra de la Pila, que, junto al que arranca del extremo occidental de la Rajica de Enmedio, determinan una superficie inclinada hacia el NW., circunstancia que se continúa aguas abajo y que es de gran interés en la comprensión de la elección de la zona beneficiada por el sistema de riego de la presa. Además, los glacis de acumulación están lacerados por la red afluente, encajada hasta el nivel de las margas miocenas. En los cauces, por lo general de fondo plano, destacan las acumulaciones de aluviones que los tapizan. De esta forma, se aprecia que sobre un sustrato impermeable -margas miocenas- yacen materiales cuaternarios que desempeñan un importante papel como posible acuífero subsuperficial, sobre todo si se tiene en cuenta su estratigrafía y composición ${ }^{1}$.

El punto en el que se localiza la presa es, por tanto, lugar en el que confluye la escorrentía, especialmente la procedente de la umbría de la sierra de la Pila, puesto que es la más abundante. Por otro lado, también se presenta como sector de concentración, tanto de las aguas hipogeas propias del acuífero que constituyen los glacis de acumulación, como del flujo subsuperficial característico de los aluviones de los cauces. Asimismo, estos últimos actúan como reguladores naturales de la evacuación de estas aguas subálveas.

Este último rasgo merece ser resaltado, puesto que la cuenca se incluye dentro de la región climática del SE peninsular, con todas las connotaciones que esto implica, es decir, acusada indigencia pluviométrica, con totales anuales en torno a $300 \mathrm{~mm}$ (Jumilla 292,3 mm, o La Raja $310,00 \mathrm{~mm})^{2}$, sequía estival, y precipitaciones concentradas en el tiempo, circunstancias que, junto al predominio de litofacies impermeables y una densa red de avenamiento, justifican que el régimen de estas ramblas sea espasmódico, caracterizado por notables avenidas que colman sus cauces habitualmente secos. Es en estos episodios de avenida cuando existen posibilidades de aprovechamiento de las aguas para riego; y ésta es la principal función de la presa de Román, el sistema de partición y boquera, pero no la única. Así, tras la crecida, y a tenor de la débil velocidad de transmisión, glacis de acumulación y aluviones, propician un caudal nada despreciable que se aprovecha mediante un cimbre, acequia y alberca. La oportunidad de este beneficio deriva no sólo de su existencia, sino también del hecho de que la presa se sitúa en el punto en el que se interrumpen longitudinalmente los aluviones, afloran pudingas, areniscas y margas, contacto de materiales que propicia la surgencia del flujo subsuperficial y su aprovechamiento.

Los materiales citados se corresponden con el conjunto de crestas monoclinales que constituye la Rajica de Enmedio, y su existencia, o mejor, su relación con la presa no es casual. En efecto, el trazado de un obstáculo transversal en el curso de una rambla precisa de un apoyo coherente, y éste no es otro que el estrato de pudingas. El estribo izquierdo de la presa, el aliviadero y el partidor tienen como cimientos las citadas pudingas, al igual que el muro de la boquera y la propia acequia del cimbre. En la margen izquierda de la rambla,

${ }^{1}$ MORALES GIL, A.: El altiplano de Jumilla-Yecla, Departamento de Geografía. Universidad de Murcia, Murcia, 1972, pp. 53-56.

${ }^{2}$ MORALES GIL, A. El Altiplano de...., Op. cit., 1972, p. 70. 


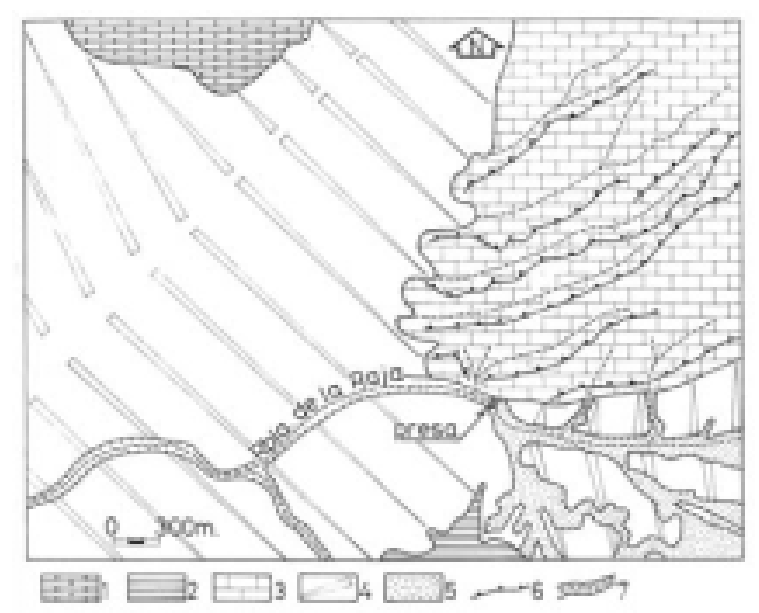

FIGURA 1. Croquis geomorfológico del entorno de la presa de Román. 2. Estribaciones meridionales de la Sierra de la Pila; 3. Monoclinales de la Rajica de Enmedio; 4. Glacis; 5. Aluviones; 6. Escarpe; 7. Cauce encajado con márgenes subverticales, frecuentemente acarcavados.

la situación varía radicalmente, ya que aquí el glacis de acumulación descansa sobre un afloramiento de margas tortonienses, sustrato, por tanto, de escasa coherencia y fácil erosión en el caso de que las aguas rebasen el muro de la presa. Efecto que todavía se acentúa más si se tiene en cuenta que esta margen izquierda, aunque de soslayo, coincide con la orilla cóncava de una sinuosidad del cauce. Fue preciso, pues, defender la presa de este riesgo mediante el trazado de un dique y de un contrafuerte que confiriese mayor solidez a esta parte de la construcción.

\section{La obra de fábrica}

Se trata, en realidad, de un azud para derivación de aguas de avenida y posterior canalización a través de una boquera. Aparece dispuesto oblicuamente al cauce y en él es posible distinguir, en planta, diferentes partes: estribo izquierdo, presa en arco, tramo recto de la presa, aliviadero, partidor y boquera. 


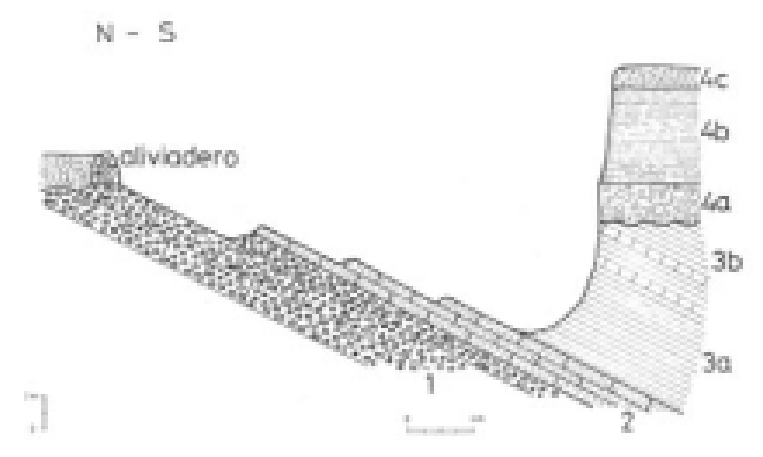

FIGURA 2. Corte transversal del cauce de la Rambla de la Raja, aguas abajo de la presa de Román. 1. Pudingas oligocenas; 2. Areniscas (posible Mioceno); 3. Tortoniense (3a. margas gris-azuladas; 3b. serie margosa con intercalaciones de calizas); 4. Cuaternario (4a. estrato heterométrico con matriz arenosa; 4b. limos y arcillas; 4c. cantos rodados con matriz areno-limosa).

El estribo izquierdo descansa sobre un potente aluvionamiento cuaternario que flanquea el cauce de la rambla del Moro en dicha margen. En planta presenta un perfil en cuña, con el vértice apuntando hacia el lecho del barranco, de $16,26 \mathrm{~m}$ de longitud total y $0,50 \mathrm{~m}$ de grosor. Está construido mediante dos muros de mampostería con argamasa y relleno de tierra entre ambos. El interior de la cuña aparece reforzado por un espaldón, igualmente, de tierra apisonada.

Apoyado en el estribo se inicia el primer tramo de la presa, cuya planta es curva, con la concavidad hacia aguas abajo. Se trata de un sistema constructivo que, por el efecto de arco, el empuje del agua se trasmite a los estribos apoyados en las márgenes. El arco presenta un desarrollo lineal notable $(26 \mathrm{~m})$ en relación con su altura $(3,10 \mathrm{~m})$, y sección trapezoidal, de forma que la anchura en coronación es de 2,6-3 m y $5 \mathrm{~m}$ en los cimientos. El paramento de aguas arriba es prácticamente vertical, con un talud de 2,10 m de altura, sobre el que descansa el muro de coronación, en arco de circunferencia, retirado de la vertical del talud 1,9 m. El paramento de aguas abajo presenta dos escalones de disipación de energía, aunque con un talud aparente casi vertical.

Este tramo de la presa está construido de mampostería a base de cantos rodados de gran tamaño, unidos con mortero de cal hidráulica. Los escalones del paramento de aguas abajo aparecen recubiertos de sillería caliza a soga.

Desde el sector central del arco, la presa disminuye progresivamente su grosor, de forma que en su vértice derecho éste es de tan sólo $0,70 \mathrm{~m}$ en el muro de coronación y 1,40 m en su base. A partir de este punto comienza el tramo recto de la presa que se desarrolla en una longitud de $14 \mathrm{~m}$ y cuyo espesor en coronación se incrementa progresivamente, 


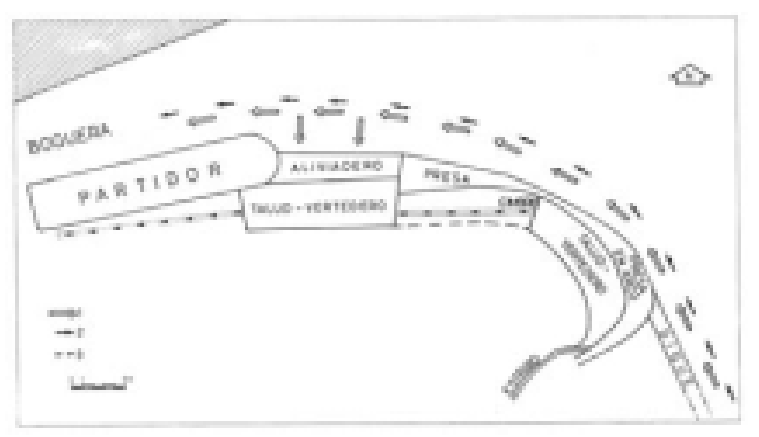

FIGURA 3. Croquis en planta del conjunto hidráulico de la presa de Román. 1. circulación de las aguas con fuertes avenidas; 2. aprovechamiento hídrico en caso de arroyadas débiles; 3. aguas permanentes alumbradas por el cimbre.

pasando de 0,70 m a 4,20 m en el contacto con el aliviadero. Ambos paramentos son, en este tramo, prácticamente verticales, tratándose de una obra de fábrica a base de muros de mampostería de piedra y cemento de argamasa y cal hidráulica.

A continuación de este tramo recto, y apoyado en su vértice interior, aparece el aliviadero que descansa, en el otro extremo, sobre el partidor de aguas. Se trata de una sólida obra de mampostería de $2 \mathrm{~m}$ de altura y alrededor de 2,80 $\mathrm{m}$ de espesor, con paramento vertical, el de aguas arriba, y ligeramente inclinado el de aguas abajo.

El último elemento señalado, el partidor, es una obra de notable envergadura, dispuesta paralelamente al lecho de la rambla y sobre su margen derecha. Presenta planta trapezoidal con esquinas redondeadas. Su longitud es de $23,7 \mathrm{~m}$, y el trapecio posee anchura decreciente, pasando de 5,30 m en el extremo de unión con el aliviadero, a 4,55 m en el opuesto. La morfología externa se caracteriza por su trazado curvo a base de mampostería y argamasa que recubren totalmente la obra en una longitud de $15,50 \mathrm{~m}$; el resto, aparece hoy desprovisto de la cobertura superior lo que permite ver el relleno interior del partidor a base de tierra compactada. En el partidor aparecen dos inscripciones significativas que permiten fechar su construcción y asignar la propiedad del terrazgo. En efecto, en la cara interior recayente a la boquera aparece esculpida sobre una losa la siguiente frase: ESTE MURO/ SEHIZO EMPODER DE/ L APODERADO DE LOS/ FALCONES LLAMA/ DO RAMON. PUCHE/. A unos 15 metros de la anterior, e igualmente esculpida en una piedra aparece la fecha 1889.

Paralela al partidor discurre la boquera para la canalización de las aguas de avenida; en su embocadura este canal tiene alrededor de $11 \mathrm{~m}$ de anchura, lo que da idea de la enorme potencia que las crecidas pueden alcanzar en esta rambla, al igual que buena prueba de ello es el hecho de que la margen de la boquera recayente al cauce se encuentre protegida por 

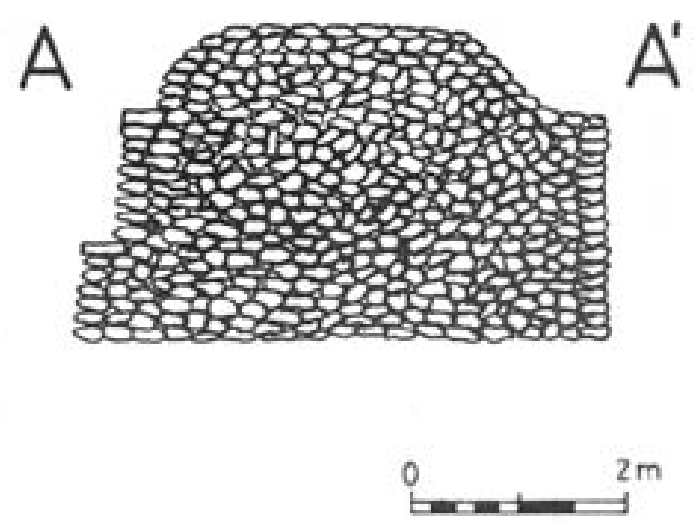

FIGURA 4. Sección transversal de la presa en arco.

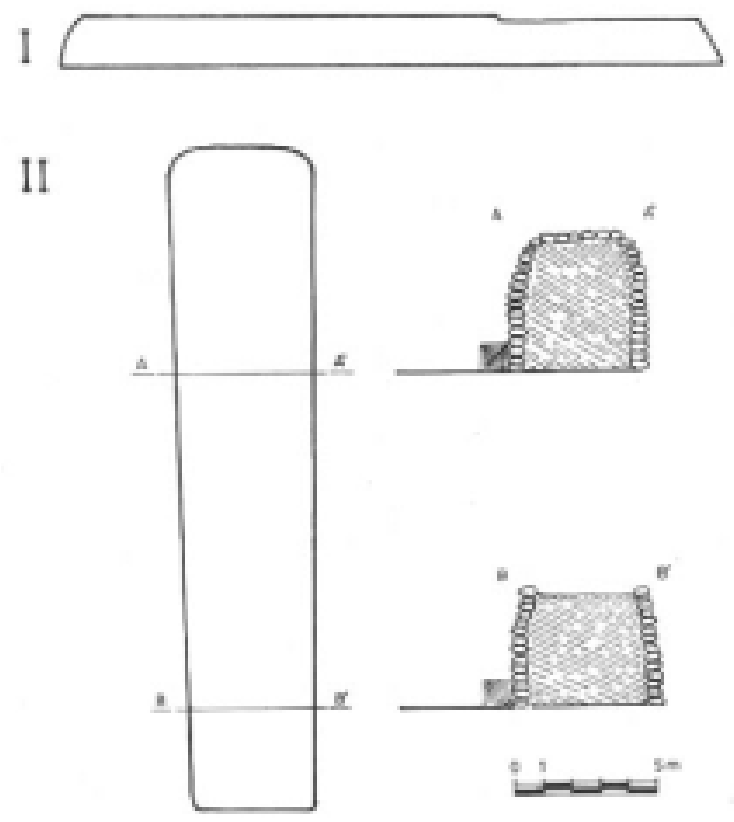

FIGURA 5. Partidor. I. sección longitudinal; II. en planta. 
un imponente murallón de mampostería, de 1.200 m de longitud, para evitar su destrucción en caso de circulación de caudales abundantes y, por supuesto, violentos. Con idéntica finalidad se procedió a la ordenación de un pequeño barranco lateral, a unos $200 \mathrm{~m}$ del inicio de la boquera, cuyo cauce, abancalado, dispone, en su tramo bajo de una pequeña presa que, en su extremo izquierdo, se bifurca en dos muros; el interior, encargado de desviar las pequeñas crecidas hacia la boquera, y el exterior, a cuyo pie se sitúa una perforación en túnel que atraviesa la boquera y el murallón que la sostiene y vierte directamente a la rambla. Esta segunda construcción tiene como objetivo canalizar las aguas de crecidas importantes evitando así la destrucción del murallón que sostiene la boquera y, en definitiva, la ruina del complejo hidráulico situado aguas arriba.

Completando la infraestructura de la presa aparecen otros tres elementos que otorgan singularidad a la obra. De un lado, en el paramento de aguas arriba, y por su margen izquierda, existe un muro-guía de mampostería -de $31 \mathrm{~m}$ de longitud, $3 \mathrm{~m}$ de altura y $1,70 \mathrm{~m}$ de grosor-, que tiene como misión desviar el agua hacia el lado derecho de la rambla, permitiendo, con ello, su encauzamiento hacia la boquera y evitando, al mismo tiempo la concentración de la energía en el estribo izquierdo de la presa y su posible erosión. Tanto la presa como el aliviadero presentan en la base del paramento de aguas abajo un sólido talud, de alrededor de $45^{\circ}$ de inclinación, construido a base de mampostería de gruesos cantos rodados y cemento de argamasa, que descansa sobre las pudingas que afloran en el cauce, y que tiene como misión evitar la socavación de la presa y el aliviadero en el caso de que las aguas rebasasen su coronación. El tercer y último elemento singular es el cimbre que se ubica en la intersección del tramo recto de la presa y el inicio del arco de la misma. Como ya se ha indicado, su objetivo es el de captar la escorrentía subsuperficial circulante por la rambla, y para ello se dispuso una perforación en túnel que atraviesa la presa y sangra los aluviones retenidos aguas arriba. La parte visible del cimbre, en el paramento de aguas abajo, aparece integrado por una galería de 3,50 m de longitud, cubierta de mampostería y con coronación ligeramente curva, destacando el hecho de que en la hilada superior los cantos aparecen dispuestos verticalmente para ofrecer mayor resistencia a la erosión de las aguas. La galería de avenamiento posee, en su embocadura, una sección de 1,10 $\mathrm{m}$ de altura por $0,70 \mathrm{~m}$ de ancho, y de ella parte un canal que conduce las aguas, prácticamente permanentes del cimbre. Este canal aparecía recubierto por el talud de la base hasta el punto en que rebasaba el aliviadero, con el objeto de evitar su ruina en caso de que las aguas saltasen por el mismo; a partir de aquí, el canal discurre a cielo abierto, sobreelevado, por la margen derecha de la rambla, y paralelo a la boquera.

\section{El aprovechamiento hídrico}

La presa de Román constituye un complejo hidráulico de marcada notoriedad, evidencia clara de la importancia del agua en el árido sureste peninsular. Del análisis detallado de sus diferentes partes se vislumbra un doble aprovechamiento hídrico; de un lado, y merced a una escorrentía hipodérmica prácticamente continua, la presa, y el cimbre a ella asociado, proporciona un caudal permanente de alrededor de 201/s, conducido a través de un canal de $1.750 \mathrm{~m}$ de longitud hasta un estanque situado al noreste de la actual casa de Román. De otro lado, el azud tenía como misión desviar las avenidas generadas por la confluencia de escorrentías sobre la cabecera de la rambla, crecidas que, en ocasiones, debían ser de notable envergadura tal y como se deduce de la sección de la boquera y del extenso predio beneficiado antaño por estas aguas eventuales, con algo más de 1.000 hectáreas. Sin olvidar, por supuesto, los posibles caudales que, una vez devueltos a la rambla a través del 
aliviadero, eran aprovechados por una segunda presa situada unos dos kilómetros aguas abajo de la que ahora se analiza y, actualmente, arruinada en su totalidad.

Una serie de detalles parecen apuntar hacia un posible origen romano de la presa. Efectivamente, tanto en la base de la misma como en el talud aparecen restos de opus incertum, técnica utilizada por los romanos en la construcción de obras de fábrica y caracterizada por el empleo de cantos rodados unidos mediante cemento de argamasa en el que se incluyen fragmentos de cerámica como elemento de cohesión. Pero, además, su funcionalidad en dicha época puede quedar, igualmente justificada, por el hecho de que, como se ha indicado, el canal de aguas permanentes, concluye en un estanque, construcción hoy completamente alterada pero de la que todavía subsisten algunos fragmentos que permiten reconstruir su fisonomía primitiva. En origen esta balsa debía tener sección cuadrada de $31 \mathrm{~m}$ de lado y en torno a $2 \mathrm{~m}$ de profundidad, con capacidad para almacenar unos $2.000 \mathrm{~m}^{3}$. Los restos todavía visibles permiten establecer su construcción mediante opus signinum. En 1951, este embalse sufrió una remodelación que minoró sus dimensiones $(31 \times 10,60 \times 2 \mathrm{~m})$ y remozó la obra de fábrica. La parte no funcional del embalse se encuentra hoy prácticamente cubierta por los légamos extraídos de la limpieza periódica del mismo y por un camino.

Desde este embalse posiblemente se procedería al abastecimiento de agua a las viliae romanas instaladas en sus inmediaciones ${ }^{3}$, a través de diferentes canalizaciones, de las cuales hasta tiempos relativamente recientes subsistió alguna, como la que concluía en la llamada «Venta de Román» situada en las proximidades del actual puente de la carretera nacional 344 que une el Puerto de la Losilla con Jumilla. Esta venta constituyó durante largo tiempo un enclave importante en el sistema de comunicaciones de la región murciana, tal y como se deduce de diferentes referencias históricas, sobre todo, la contenida en el Catastro de Ensenada: «...y una venta que se halla a distancia de tres leguas de esta Villa (Jumilla), en el sitio o Partido que llaman de Román, por lo que se la da el mismo nombre, y pertenece a don Francisco de los Covos y Galiano, vecino de Yecla, y está arrendada en mil doscientos sesenta reales vellón al año» ${ }^{4}$. Es posible que, con el tiempo, los descendientes de Francisco de los Covos pasaran a detentar, por coyundas matrimoniales con la familia Falcón, que aparece en la inscripción del partidor como promotora de su construcción en 1889, la propiedad del paraje pues, en la década de los años setenta del siglo actual, uno de los mayores propietarios de Jumilla era la familia Falcón Pérez de los Cobos, cuyos predios se localizaban en la finca del Aljunzarejo, a un kilómetro al norte de la venta y dominando, por el sureste, el terrazgo situado hasta la presa de Román.

La red de distribución de aguas de avenida es la de mayores dimensiones en sección y longitud. Prácticamente ha permanecido funcional hasta la década de los años sesenta del siglo actual, en que se inicia un intenso proceso de transformación agrícola por parte de sus propietarios, la familia Falcón Pérez de los Cobos. Las alteraciones han afectado a la trama de canales secundarios que prácticamente ha quedado desdibujada, y únicamente hoy es visible el canal principal -boquera- en sus más de $1.750 \mathrm{~m}$ de longitud, desde la presa hasta las proximidades de la Casa de Román, e incluso, el tramo que desciende hasta la venta. El resto de la red ha podido ser reconstruido mediante los fotogramas aéreos de 1956, en los que se contabiliza alrededor de 7.000 metros de boqueras secundarias y cerca de $12.000 \mathrm{~m}$ de canales de distribución entre las parcelas. Esta densa malla sólo se justifica si se tiene en cuenta que la boquera principal puede llegar a permitir el paso, en su

\footnotetext{
${ }^{3}$ MOLINA GRANDE, M.: Carta arqueológica de Jumilla. Tesis de Licenciatura inédita. Departamento de Arte y Arqueología, Univ. de Murcia, 1968, 278 folios mecanografiados.

${ }^{4}$ Jumilla. 1755. Según las Respuestas Generales del Catastro de Ensenada. Introducción de A. Morales Gil, Edit. Tabapress (Grupo Tabacalera), Madrid, 1990, p. 67.
} 


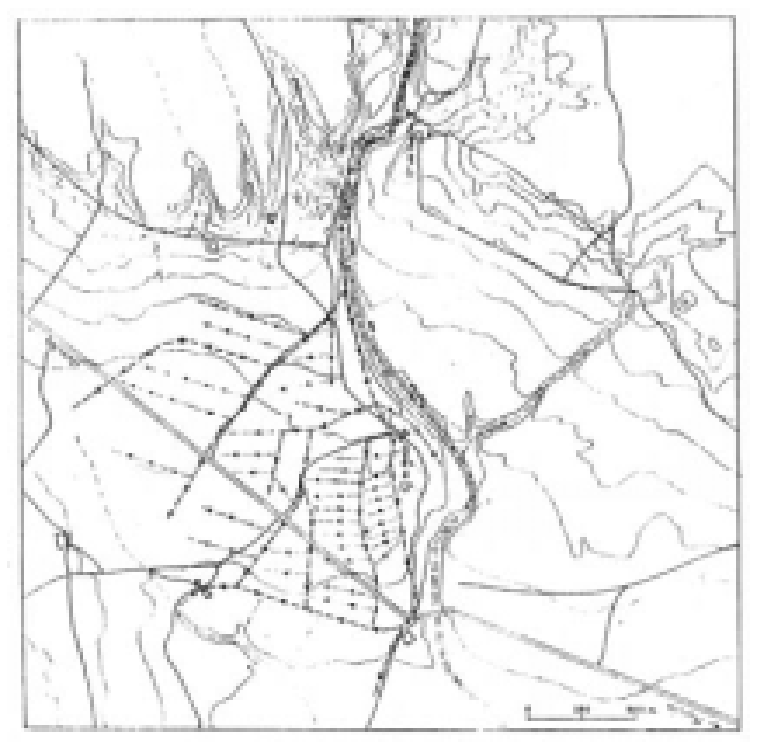

FIGURA 6. Reconstrucción a partir de la fotografía aérea de 1956 de la red de boqueras para distribuir las aguas de avenida (A. MORALES GIL, 1968).

embocadura, de más de $10 \mathrm{~m}^{3} / \mathrm{s}$, aunque este caudal se registraría en muy contadas ocasiones, siendo normal, con crecidas de tipo medio, circulaciones del orden de $5 \mathrm{~m}^{3} / \mathrm{s}$ y durante un tiempo no superior a 15 ó 20 horas, dado el régimen esporádico de funcionamiento de estas ramblas 5 .

Con crecidas de menores proporciones, el aprovechamiento de los caudales circulantes por la rambla y desviados hacia la boquera debió estar reglamentado y sujeto a derecho consuetudinario. Dos razones parecen indicar que el terrazgo beneficiado por estas aguas era el comprendido entre la Casa de Román, margen derecha de la rambla, Venta y Casa

${ }^{5}$ MORALES GIL, A.: «El riego con aguas de avenida en las laderas subáridas», Papeles del Departamento de Geografía $n .^{\circ} l$. Universidad de Murcia, 1968, pp. 176-177. 


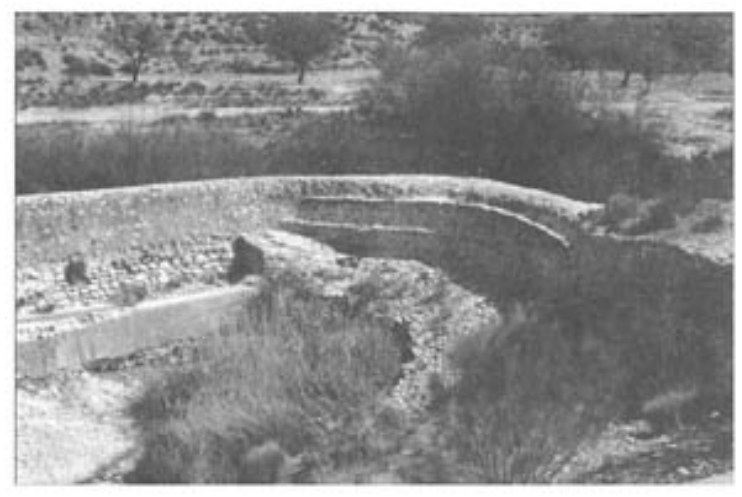

FOTO 1. Paramento de aguas abajo de la presa de Román. De derecha a izquierda de la imagen se observa: estribo; presa en arco, a cuyo pie se sitúa el talud-vertedero; tramo recto de la presa; cimbre y canal de aguas permanentes.

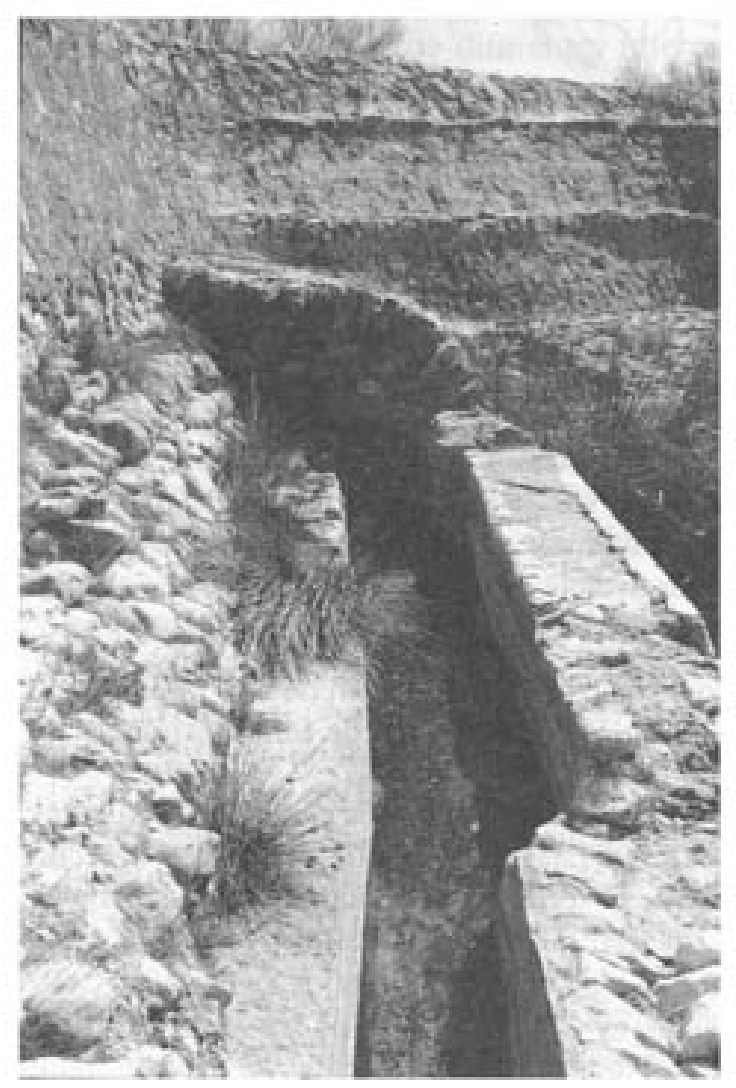

FOTO 2. Cimbre y canal de aguas permanente, obras encaminadas a aprovechar los flujos subsuperficiales de los aluviones retenidos por la presa. 


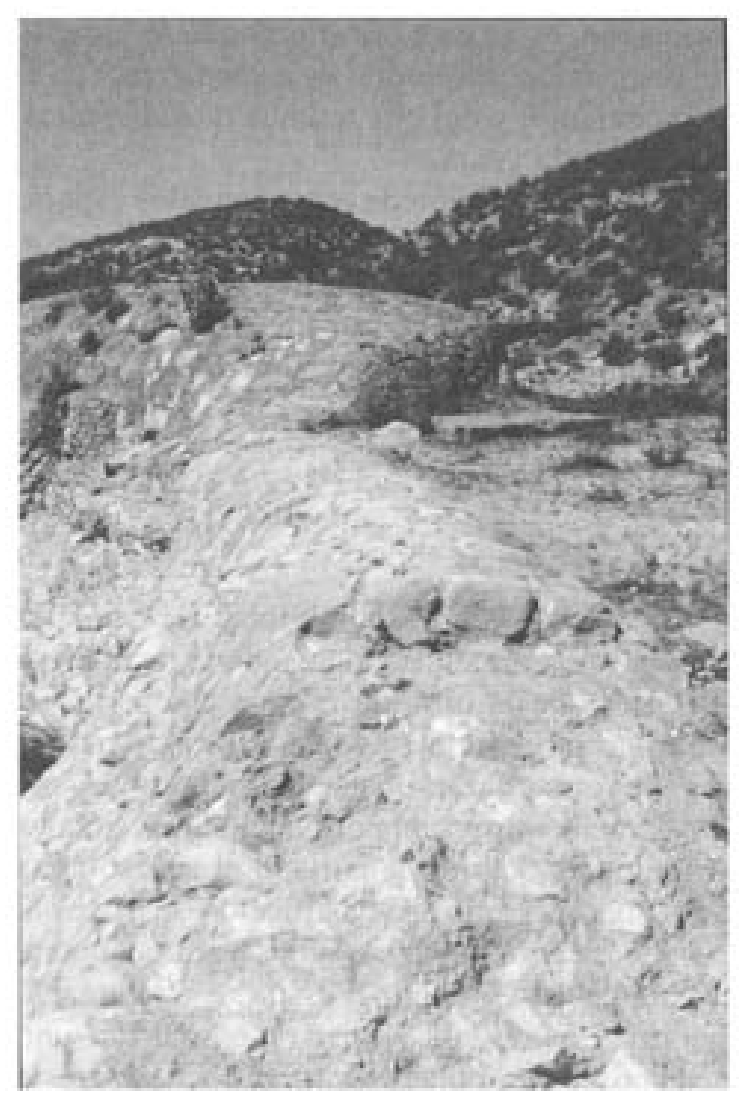

FOTO 3. Aliviadero (en primer término) y partidor de aguas (en segundo plano). Obsérvese la sólida construcción de ambas obras de fábrica.

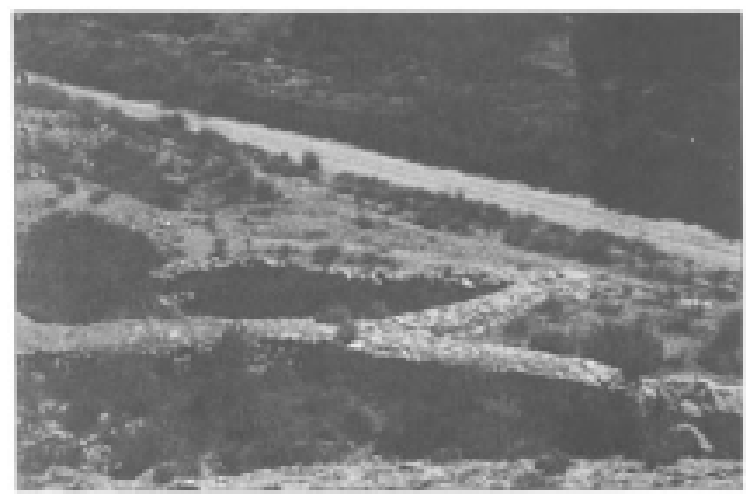

FOTO 4. Presa situada en la parte baja del barranco afluente a la boquera. 
del Aljunzarejo, así, hasta su reciente transformación, es en este espacio donde se localiza la red más densa de boqueras, y, asimismo, la dedicación primordial de estas tierras fue el olivar, cultivo exigente en humedad para su crecimiento, y del que todavía quedan restos, así como del parcelario antiguo en la zona próxima a la venta.

El área beneficiada superaría las 500 ha, si bien la aplicación de estos caudales esporádicos se efectuaría con mayor asiduidad a las, alrededor de 50 ha dedicadas al olivar; el resto, según se desprende del análisis de la fotografía aérea de 1956, mantendría un cultivo básicamente cerealista. En la actualidad, todo este espacio ha sido transformado en área de cultivo de prunus y vitis, con riego permanente suministrado por la explotación del manto acuífero del HornilloSopalmo, situado al norte de la zona.

\section{Consideraciones finales}

La nueva situación creada por el cambio de cultivo y la disponibilidad de caudales permanentes para el riego, ha tenido como consecuencia inmediata el abandono de la presa de Román y, lo que resulta más grave, el deterioro de la obra de fábrica por parte del hombre, ya que la antigua boquera es hoy un camino rural por el que se accede a diferentes casas de labor situadas aguas arriba de la presa, de forma que el obstáculo que ésta supone para la circulación del agua en los momentos de crecida provoca la desviación de caudales hacia la boquera-camino rural, quedando, en múltiples ocasiones, cortado el acceso a las mencionadas fincas. Para obviar esta situación se ha procedido a la destrucción de parte del aliviadero, rebajando su altura y evitando, con ello, la entrada de las aguas por la boquera.

Ante ello cabe, pues, efectuar alguna reflexión sobre la importancia y, sin lugar a dudas, trascendencia de este tipo de construcciones. La presa de Román no es más que uno de los numerosos azudes existentes en los lechos de ramblas y barrancos del sureste peninsular, que representan el esfuerzo secular del hombre por ordenar el territorio, pero con una percepción del medio donde condiciones naturales y aprovechamiento aparecen en claro equilibrio, fundamentando la actual teoría del «ecodesarrollo» que, sin denominación específica, era ya practicada, como se puede vislumbrar en este trabajo, por la civilización romana asentada en este espacio, lo que otorga valor histórico a este conjunto hidráulico. Una utilización del medio basada en un conocimiento profundo del espacio y su dinámica natural, lo que permitió adaptarse a sus condiciones y, con ello, aprovechar al máximo cuanto del medio era posible, ejerciendo, al mismo tiempo tareas de regulación de las ramblas, laminando y controlando sus crecidas, creando suelos agrícolas con la retención de légamos e incrementando la infiltración en los suelos y, en definitiva, la recarga de acuíferos. Todo un conjunto de ventajas que el hombre actual parece haber olvidado. 